\title{
Development and evaluation of LAMP, CPA and IMSA methods for rapid detection of the AML1/ETO fusion gene in acute myeloid leukemia
}

\author{
ZHIGANG YANG ${ }^{1,2}$, WENXIN LIU ${ }^{3}$, HAIYAN LIANG $^{4}$, RUITING WEN $^{5}$ and YUMING ZHANG ${ }^{3}$ \\ ${ }^{1}$ Department of Hematology and Rheumatology, Affiliated Central People's Hospital of Zhanjiang of Guangdong \\ Medical University, Zhanjiang, Guangdong 524045; ${ }^{2}$ Laboratory of Hematology, Guangdong Medical University, \\ Zhanjiang, Guangdong 524023; ${ }^{3}$ Department of Hematology, Affiliated Hospital of Guangdong Medical \\ University, Zhanjiang, Guangdong 524001; ${ }^{4}$ Department of Hematology, Jiangmen Central Hospital Affiliated \\ Jiangmen Hospital of Sun Yat-Sen University, Jiangmen, Guangdong 529030; ${ }^{5}$ Department of Hematopoietic \\ Stem Cell Transplantation, The 307th Hospital of The People's Liberation Army, Beijing 100071, P.R. China
}

Received February 17, 2018; Accepted June 29, 2018

DOI: $10.3892 / \mathrm{etm} .2018 .6617$

\begin{abstract}
The objective of the present study was to determine whether the loop-mediated isothermal amplification (LAMP), cross-priming amplification (CPA), and/or isothermal multiple-self-matching-initiated amplification (IMSA) methods can provide rapid detection of the runt related transcription factor $1 /$ runt related transcription factor 1 translocation partner 1 (AML1/ETO) fusion gene in acute myeloid leukemia (AML). According to the sequence of the AML1/ETO fusion gene available in GenBank and the principles of the LAMP, CPA and IMSA methods, specific primers were designed to bind a conserved region of the AML1/ETO gene in each assay. Following optimization of the conditions for the LAMP, CPA and IMSA assays, the specificity and sensitivity of the assays were examined and compared. In addition, 41 clinical samples were assayed using the three methods. It was observed that a ladder-like pattern of DNA products was produced in AML1/ETO-positive samples in all three assays, whereas no DNA product was generated with the controls. The detection limit of the LAMP and CPA assays was 50 copies/tube, and for the IMSA assay was 10 copies/tube. This sensitivity was consistent, and improved in the latter case, compared with that of the reverse transcription-polymerase chain reaction (RT-PCR) assay. Furthermore, the detection rate for bone marrow or peripheral blood samples was $9.76 \%$, and the agreement among the LAMP, CPA, IMSA and RT-PCR methods was $100 \%$.
\end{abstract}

Correspondence to: Dr Zhigang Yang, Department of Hematology and Rheumatology, Affiliated Central People's Hospital of Zhanjiang of Guangdong Medical University, 236 Yuanzhu Road, Zhanjiang, Guangdong 524045, P.R. China

E-mail: yangzg@gdmu.edu.cn

Key words: thermal amplification, loop-mediated isothermal amplification, cross-priming amplification, isothermal multiple-selfmatching-initiated amplification, AML1/ETO
Therefore, the LAMP, CPA and IMSA methods optimized in the present study provided rapid detection of the AML1/ETO fusion gene for an initial clinical diagnosis of AML. In addition, the LAMP, CPA and IMSA assays are straightforward to perform and do not require specialized instruments. Therefore, these three isothermal methods may be used to perform field tests or assays at resource-limited hospitals.

\section{Introduction}

Acute myeloid leukemia (AML) is a heterogeneous disease involving hematopoietic stem cells. Various clonal disorders of AML result from the failure of differentiation and uncontrolled proliferation of cells. It is estimated that $\sim 15 \%$ of adults with AML carry the $t(8 ; 21)$ ( $222 ; q 22)$ chromosomal translocation $(1,2)$ which fuses the runt related transcription factor 1 (AML1, also known as RUNX1) and runt related transcription factor 1 translocation partner 1 (ETO, otherwise known as $R U N X 1 T 1$ or MTG8) genes to produce an AML1/ETO chimeric protein $(3,4)$. The AML1/ETO fusion gene is associated with $\sim 6 \%$ of M1 morphology cases of AML, according to the French-American-British classification system, and with up to $92 \%$ of M2 morphology cases (5).

To date, the methods available for the detection of the $A M L 1 / E T O$ fusion gene include reverse transcription-quantitative polymerase chain reaction (RT-qPCR) $(6,7)$ and fluorescence in situ hybridization (FISH) (8). However, these methods require expensive laboratory equipment and well-trained personnel, and these represent barriers to the widespread use of these methods, particularly in developing countries. Therefore, rapid, sensitive and affordable diagnostic methods, which can be used in resource-limited settings are urgently required.

Loop-mediated isothermal amplification (LAMP) was developed by Notomi et al (9). Briefly, LAMP can amplify nucleic acids within $\sim 1 \mathrm{~h}$ and it has a detection limit of $<10$ copies. This method uses four specially designed primers, which recognize six regions of a target DNA (Fig. 1A). 
Advantages of the LAMP assay include its ease of operation, its high degree of specificity and sensitivity, and its rapid and simple procedure compared with PCR methods. Another isothermal DNA amplification method is cross-priming amplification (CPA), which was developed by Ustar Biotechnologies (Hangzhou, China). CPA relies on the use of DNA polymerase for strand displacement activity (10) and it is characterized by a high sensitivity of amplification with the use of five primers (Fig. 1B). Furthermore, the CPA method does not require a DNA denaturation step, which makes the CPA method suitable for performing diagnostic tests in resource-poor settings. More recently, isothermal multiple-self-matching-initiated amplification (IMSA) has been developed, which is a method that utilizes an isothermal DNA amplification system. This method was developed by Ding et al and has been used to detect human enterovirus 71 and coxsackievirus A16 (11). A total of three primer pairs are required to recognize seven regions of a target DNA sequence in this assay (Fig. 1C). The IMSA method only requires a simple heating device, results are easily obtained with several detection formats, and Ding et al (12) have been improving the visual diagnosis for this method.

In the present study, three rapid and sensitive isothermal amplification methods were used to detect the AML1/ETO fusion gene: LAMP, CPA and IMSA. The sensitivity, specificity and practical use of each method for the detection of the AML1/ETO fusion gene were evaluated and compared. To the best of our knowledge, the present study is the first demonstration of the capacity for these newly developed methods to be applied to AML, which have the potential to facilitate AML-M2 monitoring in developing countries.

\section{Materials and methods}

Reagents. The following reagents were purchased as indicated: Bst 2.0 DNA polymerase large fragment (New England Biolabs, Guangzhou Ltd., Guangzhou, China), Avian Myeloblastosis Virus Reverse Transcriptase (Promega Corporation, Madison, WI, USA), dNTPs (TransGen Biotech Co., Ltd., Beijing, China), RNAiso Plus (Takara Biotechnology Co., Ltd., Dalian, China), betaine (Sigma-Aldrich; EMD Millipore, Billerica, MA, USA), SYBR-Green I (SG I) fluorescent dye (Beijing Solarbio Science \& Technology Co., Ltd., Beijing, China), PCR SuperMix (TransGen Biotech Co., Ltd.), and primers synthesized by Sangon Biotech Co., Ltd. (Shanghai, China).

Primer design. According to the sequences available for the AML1 gene (GenBank: KJ890835.1), the ETO gene (GenBank: X79990.1), and the AML1/ETO fusion gene (GenBank: S78158.1), primers for the LAMP method were designed with the assistance of Primer explorer v 4.0 (http://primerexplorer.jp/e/). Primers for the CPA and IMSA methods were also designed according to the principles of these methods (Table I) $(10,11)$. Three primers, BIP for LAMP, 1s for CPA, and RIT/FIT for IMSA, were designed to recognize binding sites at the fusion point of the AML1/ETO fusion gene (Fig. 2A-C). The primers used for PCR and FISH probes were synthesized as previously described (Table I) (13).

RNA isolation. Mononuclear cells were isolated from bone marrow (BM) and peripheral blood (PB) samples with
Lymphoprep reagent (TBD Science, Tianjin, China) and were stored at $-80^{\circ} \mathrm{C}$. Total RNA from the BM and PB samples was extracted with TRIzol reagent (Takara Biotechnology Co., Ltd.) according to the manufacturer's protocol. Each RNA sample was eluted in a final volume of $30-\mu 1$ RNase-free water.

LAMP, CPA and IMSA assays. Initially, the LAMP, CPA and IMSA assays were each performed using a total volume of $25 \mu \mathrm{l}$, which included aliquots from an isothermal master mix that contained $1.5 \mu \mathrm{l}$ Bst 2.0 DNA polymerase (8 U/ $\mu \mathrm{l}), 1 \mu \mathrm{l}$ AMV enzyme, $0.5 \mathrm{M}$ betaine, $1.0 \mathrm{mM}$ dNTPs, $2.5 \mu \mathrm{l}$ of $10 \mathrm{x}$ ThermoPol buffer (New England Biolabs, Guangzhou Ltd.), and $2 \mu \mathrm{l}$ template. For the LAMP reaction, the primer mix consisted of $\mathrm{F} 3$ and $\mathrm{B} 3$ primers at $0.2 \mu \mathrm{M}$, and FIP and BIP primers at $2 \mu \mathrm{M}$. The primer mix for CPA consisted of the 1s primer at $2.0 \mu \mathrm{M}$, the $2 \mathrm{a} / 3 \mathrm{a}$ primers at $0.8 \mu \mathrm{M}$, and the $4 \mathrm{~s} / 5 \mathrm{a}$ primers at $0.4 \mu \mathrm{M}$. For IMSA, the concentration of the outer primers, DsF/DsR, were at $0.2 \mu \mathrm{M}$, whereas the FIT/RIT and $\mathrm{SteF} / \mathrm{SteR}$ primer sets were each at $0.8 \mu \mathrm{M}$. In parallel, $\mathrm{ddH}_{2} \mathrm{O}$ was used as a negative control in these assays. All assays were performed with triplicate samples.

The reactant mixture and $1.0 \mu \mathrm{l}$ of $2,000 \mathrm{X}$ SGI fluorescent dye were added into relatively separated spaces within $0.2-\mathrm{ml}$ isothermal amplification microcentrifuge (IAM) tubes. The IAM tubes were inverted several times to mix the reactant mixture and SGI. When the reaction was complete, the samples were directly observed under visible light or UV light without opening the tubes (Fig. 3). To terminate the reactions, the tubes were incubated at $85^{\circ} \mathrm{C}$ for $5 \mathrm{~min}$.

RT-PCR analysis. The RT-PCR assay was performed in a final volume of $25 \mu \mathrm{l}$ containing $0.75 \mu \mathrm{l}$ AML1/ETO forward primer $(10 \mu \mathrm{M}), 0.75 \mu \mathrm{l}$ of $A M L 1 / E T O$ reverse primer $(10 \mu \mathrm{M}), 0.25 \mu \mathrm{l}$ of AML1/ETO probe $(10 \mu \mathrm{M}), 2 \mu 1$ template, $12.5 \mu 1$ of PCR SuperMix, and $8.75 \mu \mathrm{l}$ of deionized water. A LightCycler 480 (Roche Diagnostics GmbH, Mannheim, Germany) was used for amplification with the following cycling conditions: Initial denaturation for $30 \mathrm{sec}$ at $95^{\circ} \mathrm{C}$, followed by 40 cycles consisting of $30 \mathrm{sec}$ at $95^{\circ} \mathrm{C}, 15 \mathrm{sec}$ at $60^{\circ} \mathrm{C}$, and $10 \mathrm{sec}$ at $72^{\circ} \mathrm{C}$. Fluorescence was visualized at the end of the annealing/extension step.

Optimization of the LAMP, CPA and IMSA assays. The LAMP, CPA and IMSA reactions were optimized with regard to the temperature, Bst polymerase and $\mathrm{Mg}^{2+}$ concentrations, and incubation time. Briefly, the mixtures were incubated for 60 min at $60,61,62,63,64$, or $65^{\circ} \mathrm{C}$ to identify the optimal reaction temperature for the protocol mentioned above. Optimization of the Bst polymerase concentration was achieved by evaluating polymerase concentrations of 6,8 , 10 , and 12 units, respectively. Various concentrations of $\mathrm{Mg}^{2+}$ were used $(1.0,2.0$, and $3.0 \mathrm{mM})$. When the reaction conditions had been optimized in terms of the temperature and Bst polymerase and $\mathrm{Mg}^{2+}$ concentrations, various amplification times were assessed $(15,30,45,60,75$, and $90 \mathrm{~min})$.

Specificity of the LAMP, CPA and IMSA assays. Between October 2015 and May 2016, 5 BM or PB samples (2 males and 3 females) were collected from patients with primary leukemia aged between 17 and 52 years old at the Affiliated Hospital of Guangdong Medical University (Zhanjiang, China). These 

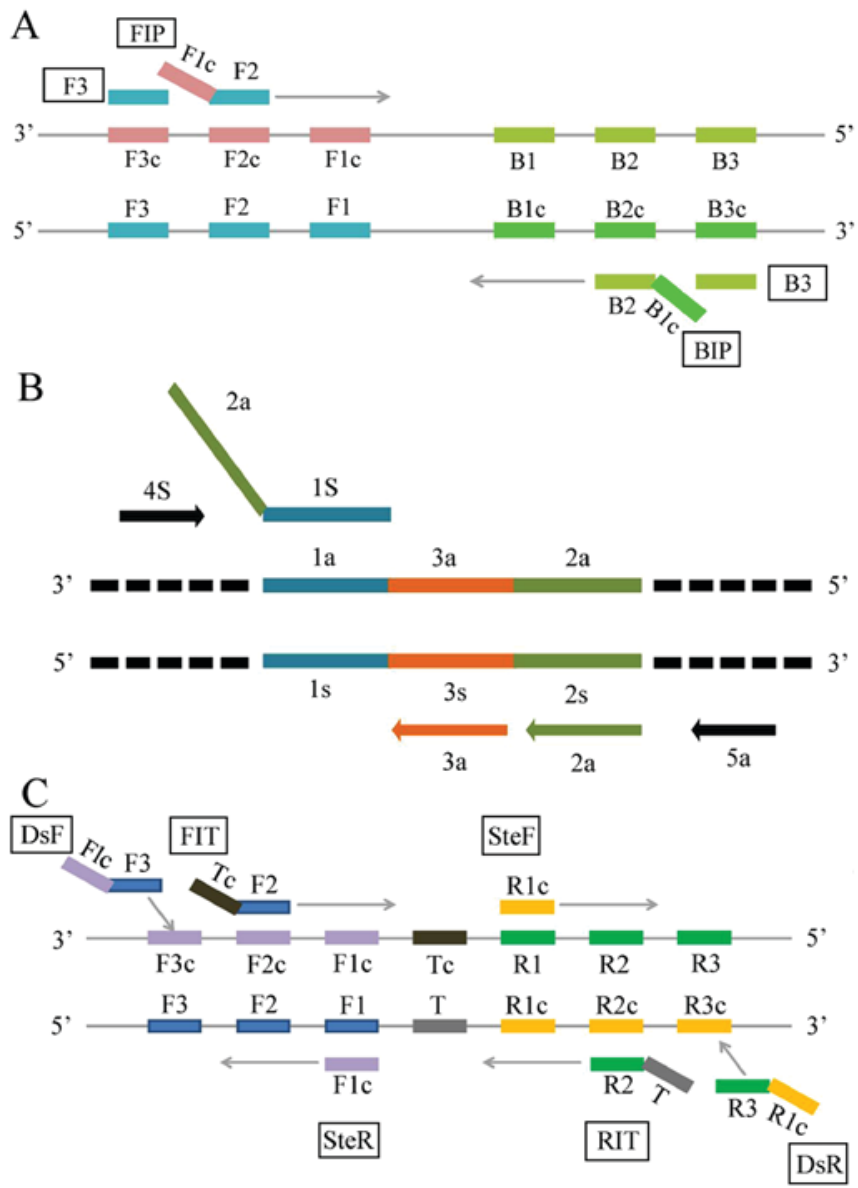

Figure 1. Illustrated overview of the amplification methods of the (A) loop-mediated isothermal amplification, (B) cross-priming amplification and (C) isothermal multiple-self-matching-initiated amplification assays. The primers specific for each assay are labelled. Arrows indicate the direction of primer extension in the target sequences. All letter-number terms represent primers or complementary regions.

patients had AML (AML1/ETO), chronic myelogenous leukemia [breakpoint cluster region (BCR)/abelson (ABL)], acute promyelocytic leukemia [promyelocytic leukemia (PML)/retinoic acid receptor- $\alpha(\mathrm{RAR} \alpha)$ ], 11q23/mixed lineage leukemia (MLL) leukemia or acute lymphocytic leukemia [(E2A/PBX homebox 1 (PBX1)]. RNA was extracted from these samples and was used to evaluate specificity of the LAMP, CPA and IMSA assays for detecting the AML1/ETO fusion gene. RNA samples from healthy individuals were used as controls. These samples were subjected to LAMP, CPA and IMSA assays, which were performed under the optimal conditions identified above.

Sensitivity of the LAMP, CPA and IMSA assays. To assess the sensitivity of the LAMP, CPA and IMSA assays for the AML1/ETO fusion gene, an AML1/ETO-positive plasmid was serially diluted $\left(10^{6}, 10^{5}, 10^{4}, 10^{3}, 10^{2}, 50,25,10\right.$, and 5 copies/tube) and detected in the LAMP, CPA and IMSA and RT-PCR assays described above. Assays at each dilution were performed in triplicate.

Detection of clinical specimens. Between October 2015 and May 2016, 41 BM or PB samples (20 males and 21 females) were collected from patients with suspected primary acute leukemia aged between 17 and 63 years old at the Affiliated
A

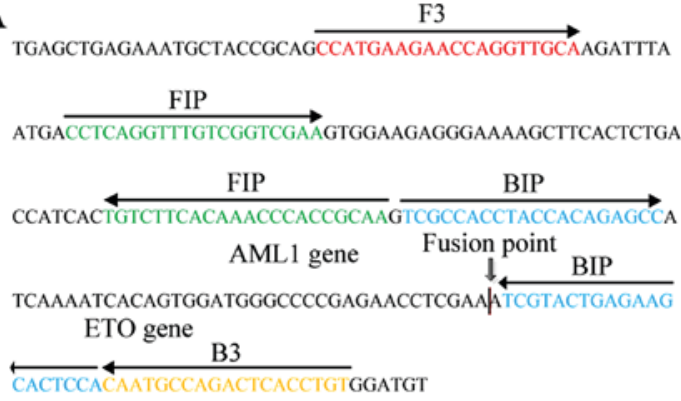

B

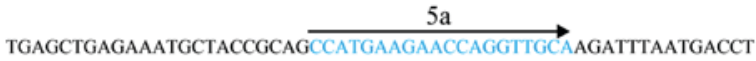

CAGGTTTGTCGGTCGAAGTGGAAGAGGGAAAAGCTTCACTCTGACCATCACTGTCTT

1s/2a AML1 gene

CACAAACCCACCGCAAGTCGCCACCTACCACAGAGCCATCAAAATCACAG $\overrightarrow{\longrightarrow G G A T G G}$

$\underset{\mathrm{GCCCCGAGAA}}{\longrightarrow} \stackrel{\text { Fusion point }}{\stackrel{4}{\text { E }} \text { ETCGAAATCGTACTGAGAAGCACTCCACAATGCCAGACTCACCTGT }}$

GGATGT

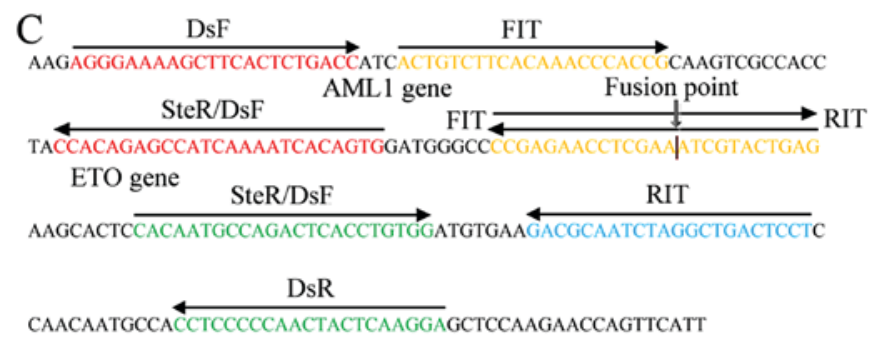

Figure 2. Orientation and binding sites of the primers designed for detection of the $A M L 1 / E T O$ region in (A) loop-mediated isothermal amplification, (B) cross-priming amplification and (C) isothermal multiple-self-matching-initiated amplification assays are indicated with arrows and colored bases. The fusion point of the AML1/ETO gene is indicated in each sequence with a vertical arrow. $A M L 1$, runt related transcription factor 1 ; ETO, runt related transcription factor 1 translocation partner 1 .

Hospital of Guangdong Medical University. These samples were subjected to LAMP, CPA and IMSA assays. RT-PCR assays were also performed on these samples.

Ethics statement. All procedures performed in the present study involving human participants were in accordance with the ethical standards of the Ethics Committee of the Affiliated Hospital of Guangdong Medical University, and with the 1964 Helsinki declaration and its later amendments or comparable ethical standards. No experiments involving animals were performed in the present study. Informed consent was obtained from all of the individuals who were involved in the study.

\section{Results}

Amplification of the AML1/ETO fusion gene by LAMP, CPA and IMSA assays. Positive samples in the LAMP, CPA and IMSA reactions exhibited a ladder-like pattern with electrophoretic separation on a $2.0 \%$ agarose gel. By contrast, this pattern was absent in the control samples (Fig. 4A-C). When the reaction products were mixed with SGI fluorescent dye, the positive samples changed color from orange to green, whereas the negative 
Table I. Primers used in LAMP, CPA, IMSA and reverse transcription-polymerase chain reaction assays.

\begin{tabular}{|c|c|c|}
\hline Assay & Primer & Sequence $\left(5^{\prime}-3^{\prime}\right)$ \\
\hline \multirow[t]{4}{*}{ LAMP } & F3 & CCATGAAGAACCAGGTTGCA \\
\hline & B3 & ACAGGTGAGTCTGGCATTG \\
\hline & FIP & TTGCGGTGGGTTTGTGAAGACA-CCTCAGGTTTGTCGGTCGA \\
\hline & BIP & TCGCCACCTACCACAGAGCC-TGGAGTGCTTCTCAGTACGA \\
\hline \multirow[t]{5}{*}{ CPA } & $1 \mathrm{~s}$ & TCGCCACCTACCACAGAGCC-TGGAGTGCTTCTCAGTACGA \\
\hline & $2 \mathrm{a}$ & TCGCCACCTACCACAGAGCC \\
\hline & $3 a$ & TGGATGGGCCCCGAGAA \\
\hline & $4 \mathrm{~s}$ & ACAGGTGAGTCTGGCATTG \\
\hline & $5 \mathrm{a}$ & CCATGAAGAACCAGGTTGCA \\
\hline \multirow[t]{6}{*}{ IMSA } & $\mathrm{DsF}$ & CACTGTGATTTTGATGGCTCTGTGG-AGGGAAAAGCTTCACTCTGACC \\
\hline & DsR & CACAATGCCAGACTCACCTGTGG-TCCTTGAGTAGTTGGGGGAGG \\
\hline & FIT & CTCAGTACGATTTCGAGGTTCTCGG-ACTGTCTTCACAAACCCACCG \\
\hline & RIT & CCGAGAACCTCGAAATCGTACTGAG-AGGAGTCAGCCTAGATTGCGTC \\
\hline & SteF & CACAATGCCAGACTCACCTGTGG \\
\hline & SteR & CACTGTGATTTTGATGGCTCTGTGG \\
\hline
\end{tabular}

LAMP, loop-mediated isothermal amplification; CPA, cross-priming amplification; IMSA, isothermal multiple-self-matching-initiated amplification.

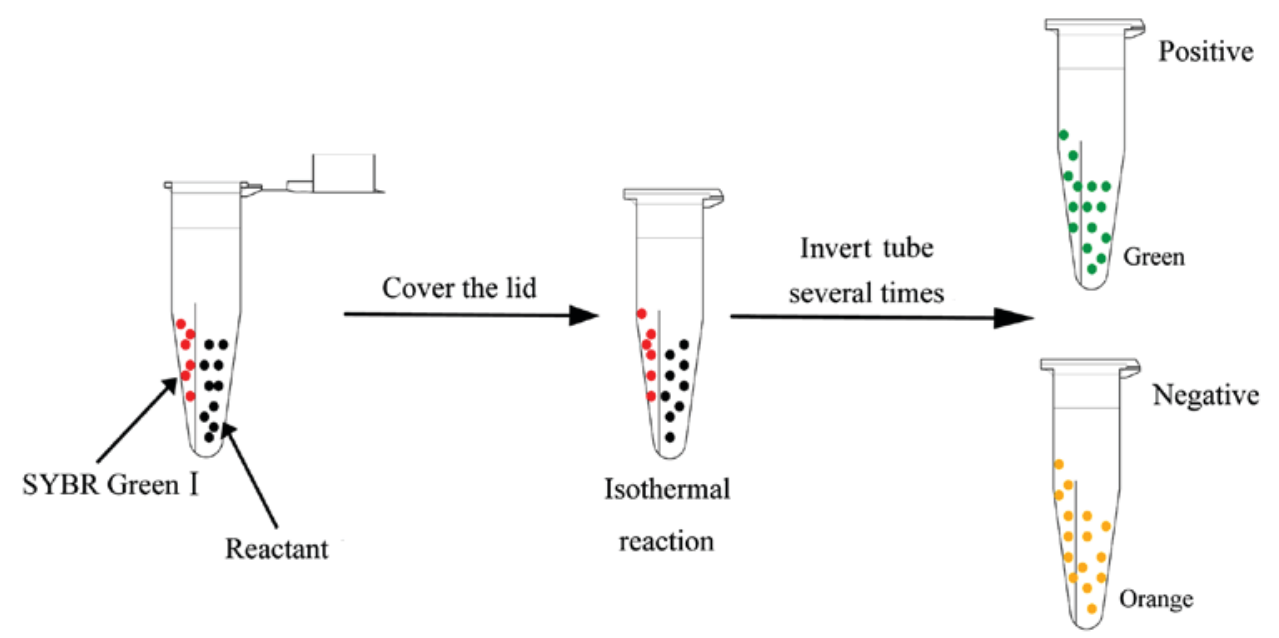

Figure 3. Illustrated overview of the reaction steps of the isothermal reactions performed in the present study. Following the addition of reactant and fluorescent dye, the reaction proceeded without opening of the reaction tube in order to limit the potential for cross-contamination.

controls remained orange in color (Fig. 4D-F). Under UV light, the positive samples exhibited a green fluorescent signal, whereas the negative controls remained dark orange in color (Fig. 4G-I).

Optimization of the assays. The optimal temperatures for the LAMP, CPA and IMSA assays were determined by varying the temperature of the assays between 60 and $65^{\circ} \mathrm{C}$ for $60 \mathrm{~min}$ and using a plasmid containing the $A M L 1 / E T O$ fusion gene as a template. For the LAMP (Fig. 5A-C), CPA (Fig. 5-D-F), and IMSA (Fig. 5G-I) assays, the optimal temperature was $60^{\circ} \mathrm{C}$ (Fig. 5A, E and I). The optimal concentrations of Bst DNA polymerase and $\mathrm{Mg}^{2+}$ in the three assays were $8 \mathrm{U} /$ tube (Fig. 5B, F and J), and 2.0, 3.0, and $2.0 \mathrm{mM}$ (Fig. 5C, G and $\mathrm{K})$, respectively. The optimal reaction time for the LAMP and CPA assays was $45 \mathrm{~min}$, and the optimal reaction time was $30 \mathrm{~min}$ for the IMSA assay (Fig. 5D, H and L).

Assay specificity. The specificity of the LAMP, CPA, and IMSA methods for detecting the AML1/ETO fusion gene was determined by assaying samples containing other fusion genes of hematologic malignancies, including $B C R / A B L$, $P M L / R A R A, 11 q 23 / M L L$ and $E 2 A / P B X 1$. Samples from healthy individuals were used as controls. Amplification products were only observed in the reaction tubes that contained the target region of the AML1/ETO fusion gene. In addition, the three isothermal assays achieved $100 \%$ specificity for the target fusion gene, and this was comparable to the detection specificity achieved with PCR analysis (Fig. 6A-I). 


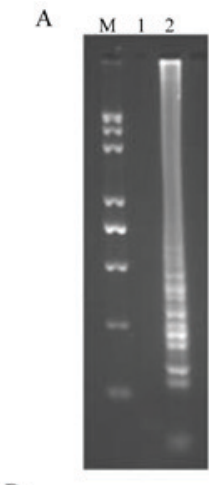

D
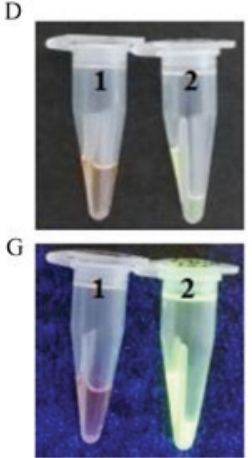

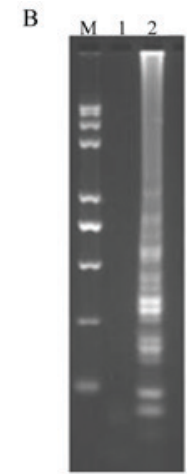

E

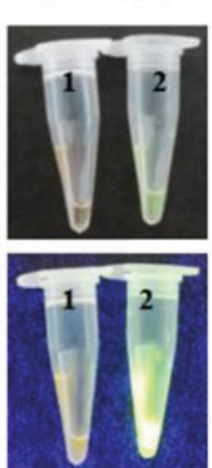

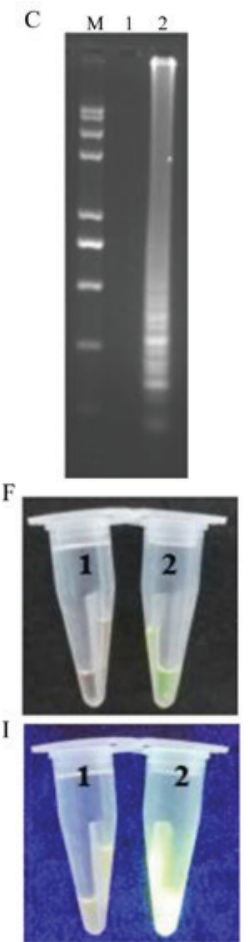

Figure 4. Representative isothermal reaction assays of negative controls and positive samples subjected to LAMP, CPA and IMSA methods to detect the AML1/ETO fusion gene. Reaction contents of the tubes for (A) LAMP, (B) CPA and (C) IMSA assays were subjected to agarose gel electrophoresis and UV visualization of the products. Images of reaction tubes for (D) LAMP, (E) CPA and (F) IMSA under visible light. Images of reaction tubes for (G) LAMP, (H) CPA and (I) IMSA under UV light. Images were captured following the addition of SYBR-Green I. LAMP, loop-mediated isothermal amplification; CPA, cross-priming amplification; IMSA, isothermal multiple-self-matching-initiated amplification; $\mathrm{M}$, Trans $2 \mathrm{~K}$ plus II DNA marker; 1, negative control; 2, positive detection of AML1/ETO fusion gene. $A M L 1$, runt related transcription factor 1 ; ETO, runt related transcription factor 1 translocation partner 1 .

Assay sensitivity. A plasmid containing the AML1/ETO fusion gene was serially diluted. Various dilutions of the plasmid were then subjected to LAMP, CPA, and IMSA assays to evaluate sensitivity. RT-PCR analysis was also performed on the diluted samples for comparison. It was observed that as few as 10 plasmid copies/tube were detected in the IMSA assay, whereas 50 plasmid copies/tube was the detection limit for the LAMP, CPA and PCR assays (Fig. 7A-J). These results demonstrated that the IMSA assay exhibited increased sensitivity in detecting the $A M L 1 / E T O$ fusion gene compared with the LAMP, CPA and RT-PCR assays.

Detection of clinical samples with LAMP, CPA and IMSA assays. A total of $41 \mathrm{BM}$ or $\mathrm{PB}$ samples were subjected to LAMP, CPA and IMSA assays to detect the AML1/ETO fusion gene. In parallel, the same samples were subjected to RT-PCR assays. The positive detection rate for all three assays was $9.76 \%$, and these results were in agreement with those from the RT-PCR assays (Fig. 8A-J).

\section{Discussion}

AML is a hyperplastic disease involved in the proliferation and abnormal differentiation of leukemia cells in BM and
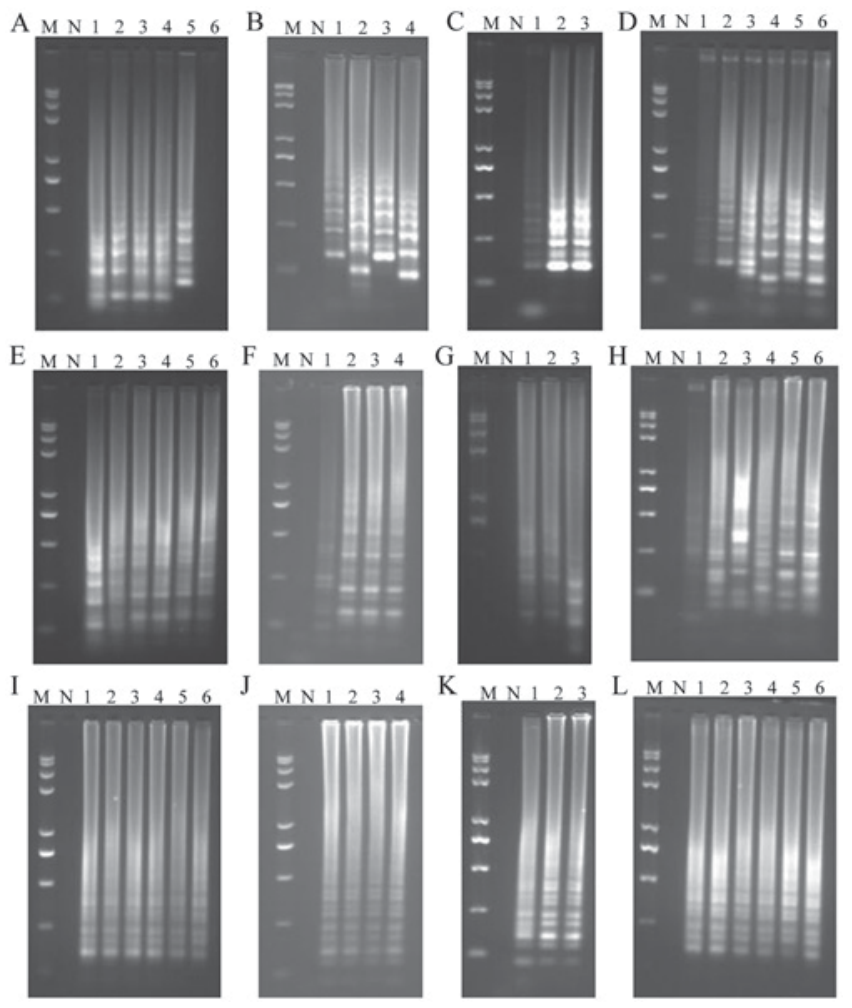

Figure 5. Optimization of LAMP, CPA and IMSA assay conditions for detection of the AML1/ETO fusion gene. Optimization of (A) temperature, (B) Bst enzyme concentration, (C) $\mathrm{Mg}^{2+}$ concentration and (D) amplification time in the LAMP assay. Optimization of (E) temperature, (F) Bst enzyme concentration, $(\mathrm{G}) \mathrm{Mg}^{2+}$ concentration and $(\mathrm{H})$ amplification time in the CPA assay. Optimization of (I) temperature, (J) Bst enzyme concentration, (K) $\mathrm{Mg}^{2+}$ concentration and (L) amplification time in the IMSA assay. Optimization of temperature was performed at $60,61,62,63,64$, and $65^{\circ} \mathrm{C}$ for samples $1-6$, respectively; optimization of $B s t$ enzyme concentration was performed with $6.0,8.0,10$, and 12 units of enzyme for samples 1-4, respectively; optimization of $\mathrm{Mg}^{2+}$ concentration was performed with $1.0,2.0$, and $3.0 \mathrm{mM} \mathrm{Mg}^{2+}$ in samples 1-3, respectively; optimization of amplification time was performed for $15,30,45,60,75$, and $90 \mathrm{~min}$ for samples $1-6$, respectively. LAMP, loop-mediated isothermal amplification; CPA, cross-priming amplification; IMSA, isothermal multiple-self-matching-initiated amplification; M, Trans 2K plus II DNA marker; $\mathrm{N}$, negative control.

$\mathrm{PB}$, and this can be a life-threatening condition (14). The crude incidence and mortality rates of leukemia in China in 2009 were $5.68 / 10^{5}$ and $4.28 / 10^{5}$, respectively. In addition, the incidence and mortality rates of myeloid leukemia were significantly higher than those for lymphoid leukemia. The incidence of AML is closely associated with the formation of oncogenic fusion genes from chromosomal translocation events, and they often represent molecular biological markers of AML (2). Therefore, the ability to detect and monitor fusion genesis is of importance to patients with AML. To date, the fusion genes of AML mainly include: $P M L-R A R A$, AML1-ETO, CBF $\beta$-MYH11, MLL/AF9, DEK/CAN, nucleophosmin $(N P M) /$ myeloid leukemia factor $1(M L F)$, $E 2 A / P B X 1$, and translocation liposarcoma (TLS)/ETS-related gene $(E R G)$, and these are of significance for the diagnosis and treatment of AML.

Among the fusion genes mentioned above, the AML1/ETO fusion gene is recognized as a classic molecular marker for $A M L-M 2$. Previously, RT-PCR was the gold standard for rapid and sensitive detection of the AML1/ETO fusion gene in 

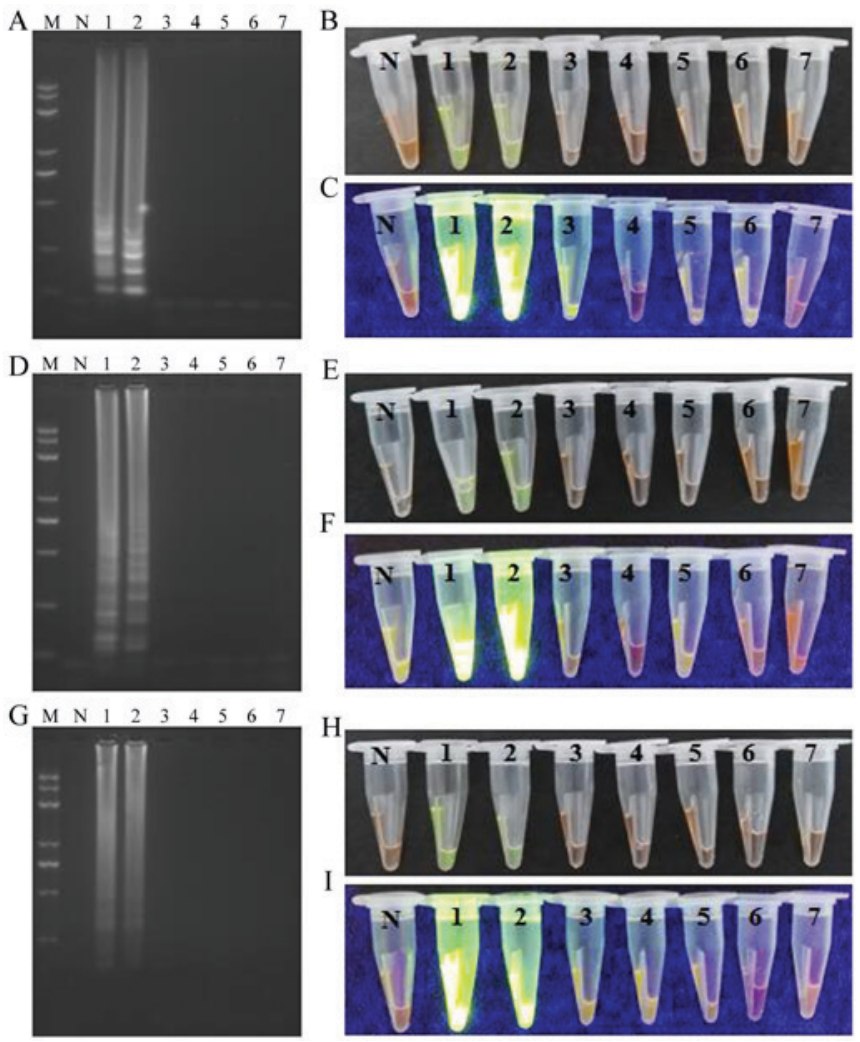

Figure 6. Specificity test for the LAMP, CPA and IMSA assays. LAMP assay: (A) Agarose gel electrophoresis of products obtained; (B) visualization of reactions performed with various samples (1-7) and SYBR-Green I under visible light; (C) visualization of reactions performed with various samples (1-7) and SYBR-Green I under UV light. CPA assay: (D) agarose gel electrophoresis of products obtained; (E) visualization of reactions performed with various samples (1-7) and SYBR-Green I under visible light; (F) visualization of reactions performed with various samples (1-7) and SYBR-Green I under UV light. IMSA assay: (G) agarose gel electrophoresis of products obtained; (H) visualization of reactions performed with various samples (1-7) and SYBR-Green I under visible light; (I) visualization of reactions performed with various samples (1-7) and SYBR-Green I under UV light. M, Trans $2 \mathrm{~K}$ plus II DNA marker; $\mathrm{N}$, negative control; LAMP, loop-mediated isothermal amplification; CPA, cross-priming amplification; IMSA, isothermal multiple-self-matching-initiated amplification; AML1/ETO, runt related transcription factor 1/runt related transcription factor 1 translocation partner 1; 1, AML1/ETO plasmid ; 2, AML1/ETO fusion gene sample; 3, chronic myelogenous leukemia (breakpoint cluster region/abelson) sample; 4 , acute promyelocytic leukemia (promyelocytic leukemia/retinoic acid receptor- $\alpha$ ) sample; 5, 11q23/mixed lineage leukemia leukemia sample; 6, acute lymphocytic leukemia/PBX homebox 1 sample; 7, healthy sample as the template.

leukemia. However, RT-PCR requires $~ 4-5$ h due to separation of the reverse transcription step and the amplification step. In the present study, these two steps were performed simultaneously, which shortened the RT-PCR protocol by 1-1.5 h. In addition, unlike conventional RT-PCR, the amplification products of LAMP, CPA and IMSA assays do not require any further manipulation as they can be visualized with fluorescent dyes, including calcein and SGI, or directly analyzed with a real-time turbidimeter. Calcein was the first dye used in isothermal reactions based on its ability to release $\mathrm{Mn}^{2+}$ upon complexation with pyrophosphate during DNA synthesis $(15,16)$. Therefore, this dye can be added into a reaction system prior to an isothermal reaction, and cross-contamination does not occur to affect the reaction. However, calcein exhibits reduced sensitivity compared with the SGI fluorescent dye and a real-time turbidimeter $(11,17)$. The use of a real-time turbidimeter also means that LAMP, CPA and IMSA assays can be quantitative techniques (18). However, turbidimeters are not widely available in developing countries due to their cost. Previously, SGI was the most common fluorescent dye used for isothermal reactions due to its high sensitivity and low cost. However, this dye is added following the reaction endpoint $(19,20)$, and the opening of a reaction tube increases the potential for cross-contamination (21). In the present study, novel IAM tubes were used in the LAMP, CPA, and IMSA reactions that were initially performed. The circumference of these tubes was such that the isothermal reaction liquid was added and remained distinct from the added SGI fluorescent dye. When the isothermal reaction was initiated, the IAM tube was inverted several times to completely mix the isothermal reaction liquid and the SGI fluorescent dye without opening the cover, therefore, minimising cross-contamination (Fig. 3).

To the best of our knowledge, the present study is the first to compare LAMP, CPA and IMSA assays in terms of detection of the AML1/ETO fusion gene. In addition, the diagnostic performance of these three thermal amplification assays was compared with that achieved with RT-PCR. In terms of sensitivity, the LAMP and CPA assays exhibited comparable sensitivity to RT-PCR (50 copies/tube). However, the IMSA assay exhibited increased sensitivity (10 copies/tube) of detection, and this result is in agreement with the results of a previous study, which demonstrated that the IMSA assay was more sensitive than the LAMP assay in the detection of human enterovirus 71 (11).

Primer specificity is important in isothermal assays. To distinguish the AML1/ETO fusion gene from other fusion genes, specific primer sets were designed for the LAMP, CPA and IMSA assays, which were all based on a region common to the AML1 gene (GenBank: KJ890835.1), the ETO gene (GenBank: X79990.1), and the AML1-ETO fusion gene (GenBank: S78158.1). Specifically, BIP, 1s, and RIT/FIT primers, respectively, were designed to bind the fusion point of the AML1/ETO fusion gene. To determine the specificity of these primers, the AML1/ETO fusion gene and four other fusion genes associated with malignant tumors of the hematological system were assayed in parallel. A high degree of specificity in detection of the AML1/ETO fusion gene was observed, and no false-positive results were obtained. Therefore, the LAMP, CPA and IMSA assays exhibited high specificity for the AML1/ETO target. Of note, only four fusion genes were selected to serve as negative controls in the evaluation of assay specificity due to the limited availability of other fusion genes. It was hypothesized that primers with increased specificity prevent the detection of other fusion genes as false-positives, and this can be assessed in future investigations by assaying additional fusion genes to provide data to further characterize the sensitivity of isothermal assays.

A practical evaluation of the LAMP, CPA and IMSA assays was performed with detection of the AML1/ETO fusion gene in 41 clinical samples. An RT-PCR assay of these samples was performed in parallel, and 4/41 clinical samples were identified as positive for the AML1/ETO fusion gene. The LAMP, CPA and IMSA assays produced the same result. Taken together, these results confirmed that the LAMP, CPA and IMSA assays, which were optimized in the present study, exhibited comparable sensitivity and specificity to RT-PCR assays in detecting 
A M $1 \begin{array}{llllllllllll}1 & 2 & 3 & 4 & 5 & 6 & 7 & 8 & 9 & \mathbf{N} & \mathrm{B}\end{array}$
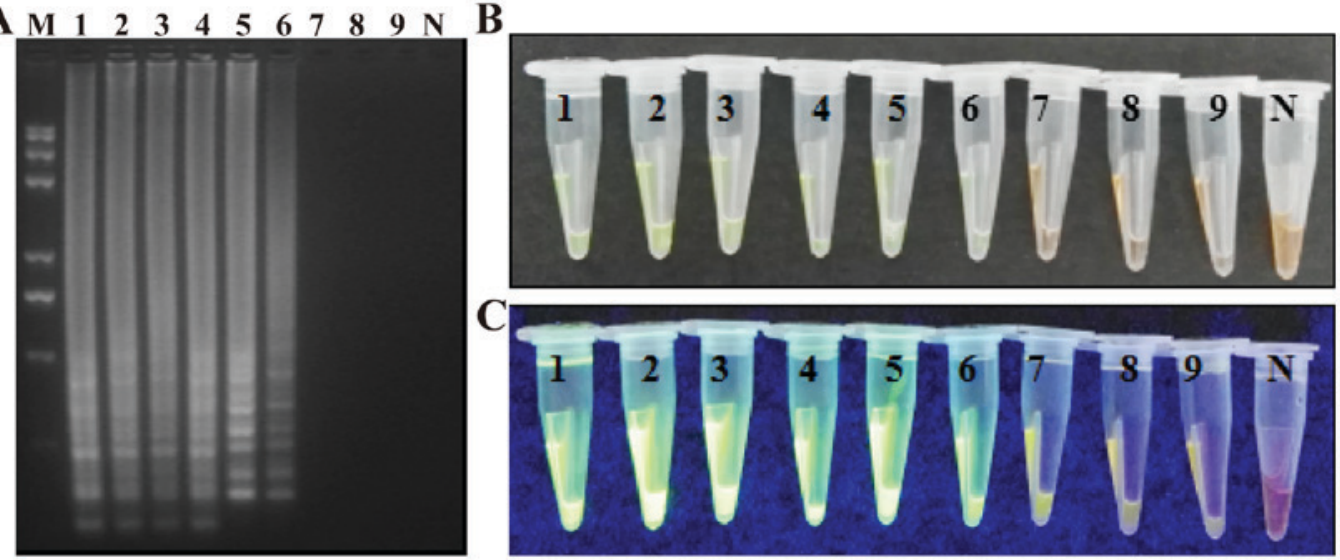

D \begin{tabular}{lllllllllll}
\hline & 1 & 2 & 3 & 4 & 5 & 6 & 7 & 8 & 9 & $N$
\end{tabular}
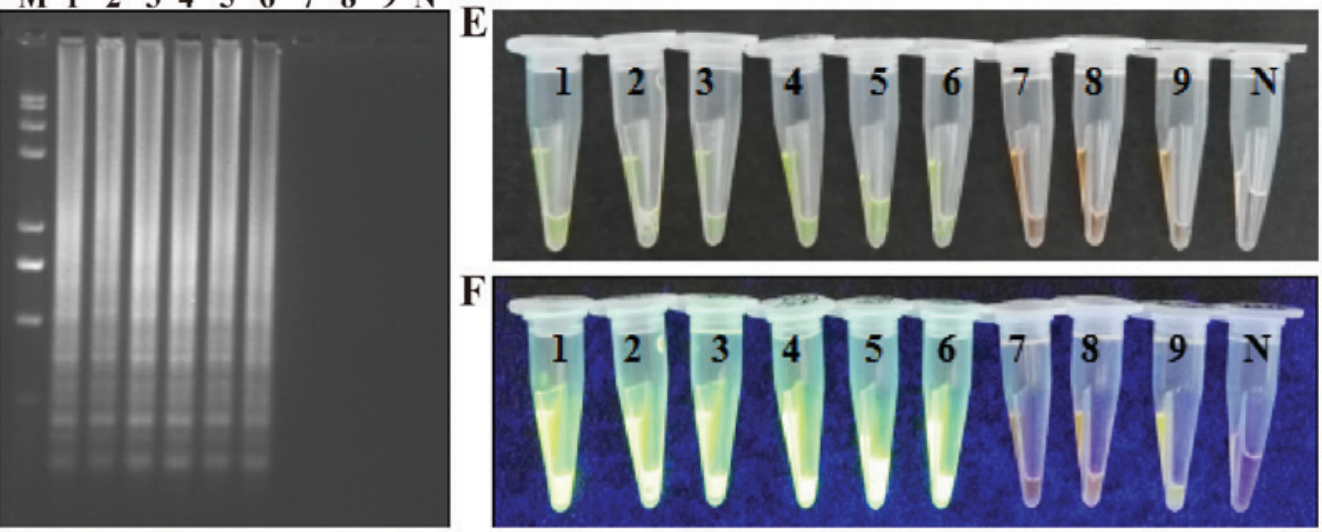

GM $1 \begin{array}{llllllllll}1 & 2 & 3 & 4 & 5 & 6 & 7 & 8 & 9 & \mathrm{~N}\end{array}$
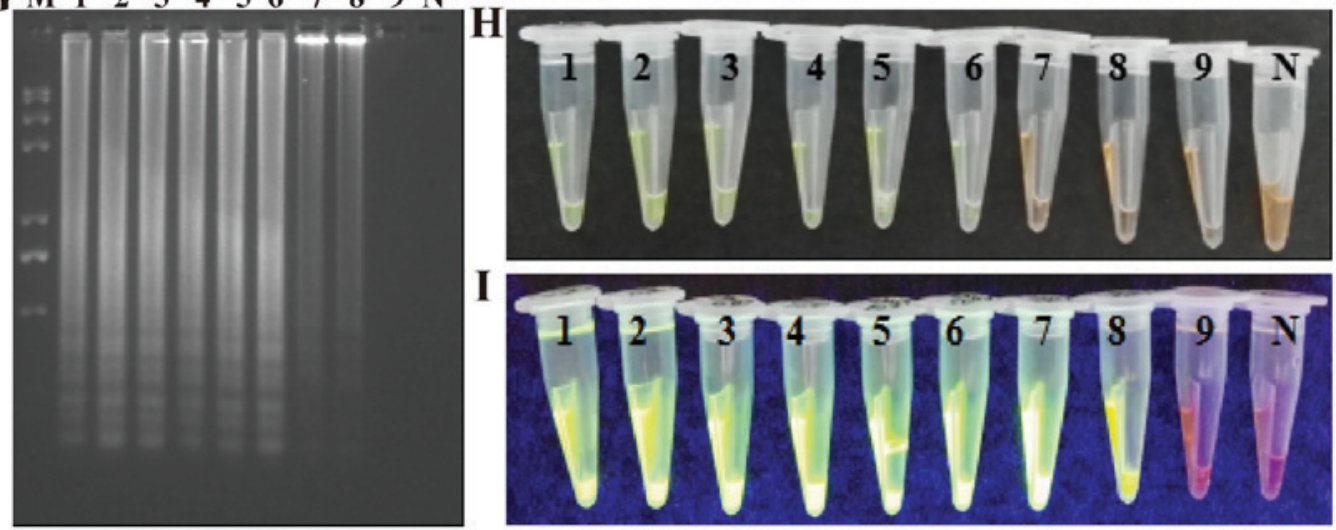

$\mathbf{J}$

Amplification Curves

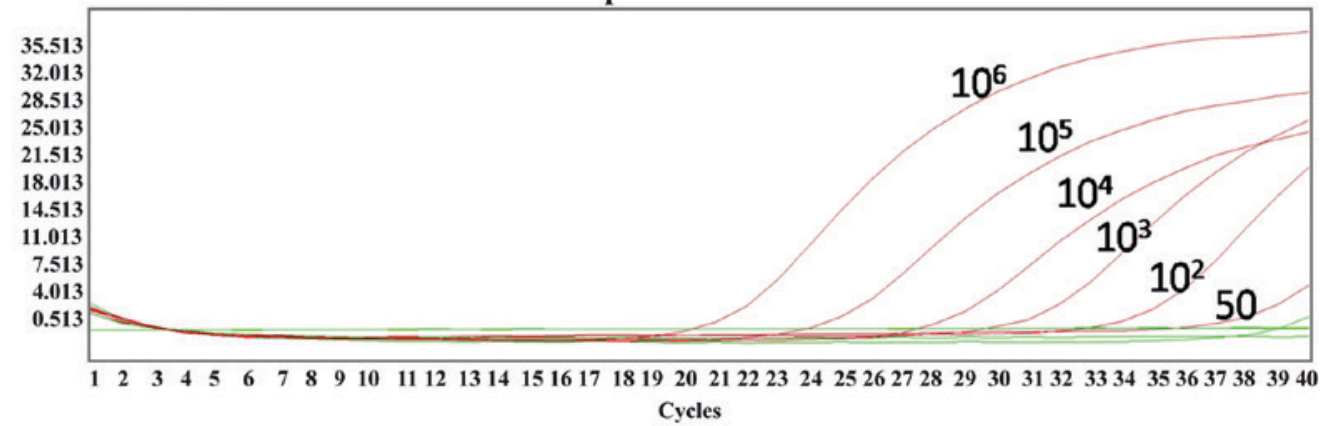

Figure 7. Sensitivity test for the LAMP, CPA and IMSA assays. LAMP assay: (A) Agarose gel electrophoresis of the products; (B) visualization of reactions performed with serially diluted ABL1-ETO fusion gene plasmids (1-9) and SYBR-Green I under visible light; (C) visualization of reactions performed with various fusion gene samples (1-9) and SYBR-Green I under UV light. CPA assay: (D) agarose gel electrophoresis of the products; (E) visualization of reactions performed with serially diluted ABL1-ETO fusion gene plasmids (1-9) and SYBR-Green I under visible light; (F) visualization of reactions performed with various fusion gene samples (1-9) and SYBR-Green I under UV light. IMSA assay: (G) agarose gel electrophoresis of the products; (H) visualization of reactions performed with serially diluted ABL1-ETO fusion gene plasmids (1-9) and SYBR-Green I under visible light; (I) visualization of reactions performed with various fusion gene samples (1-9) and SYBR-Green I under UV light. (J) Reverse transcription-polymerase chain reaction amplification curves for samples 1-9. LAMP, loop-mediated isothermal amplification; CPA, cross-priming amplification; IMSA, isothermal multiple-self-matching-initiated amplification; M, Trans 2K plus II DNA marker; $1-9,10^{6}, 10^{5}, 10^{4}, 10^{3}, 10^{2}, 50,25,10$, and 5 plasmid copies/tube, respectively; $\mathrm{N}$, negative control. 


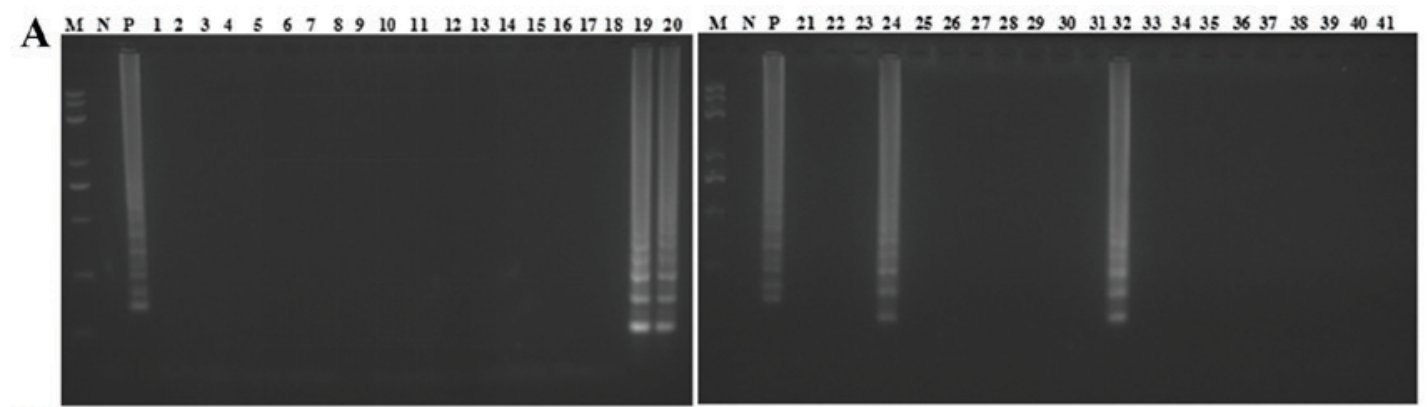

B

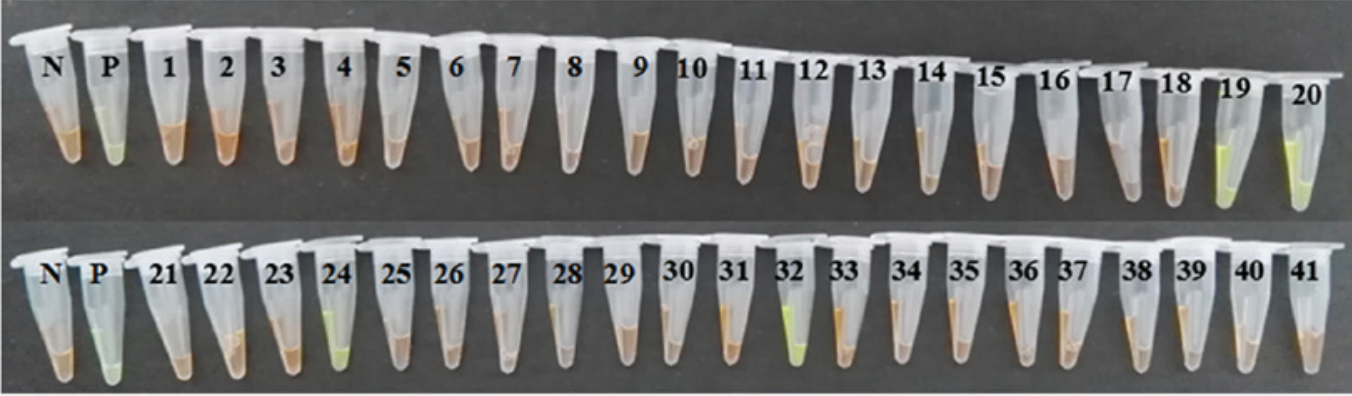

$\mathrm{C}$

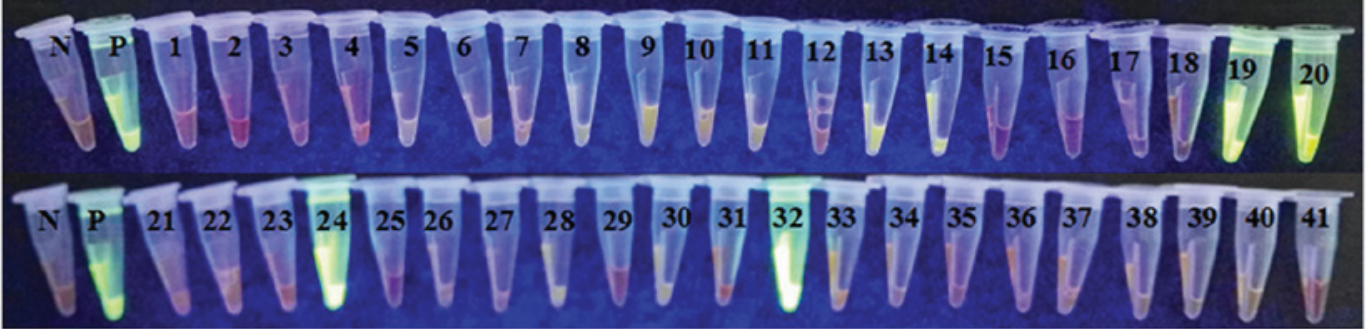

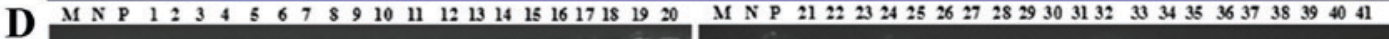

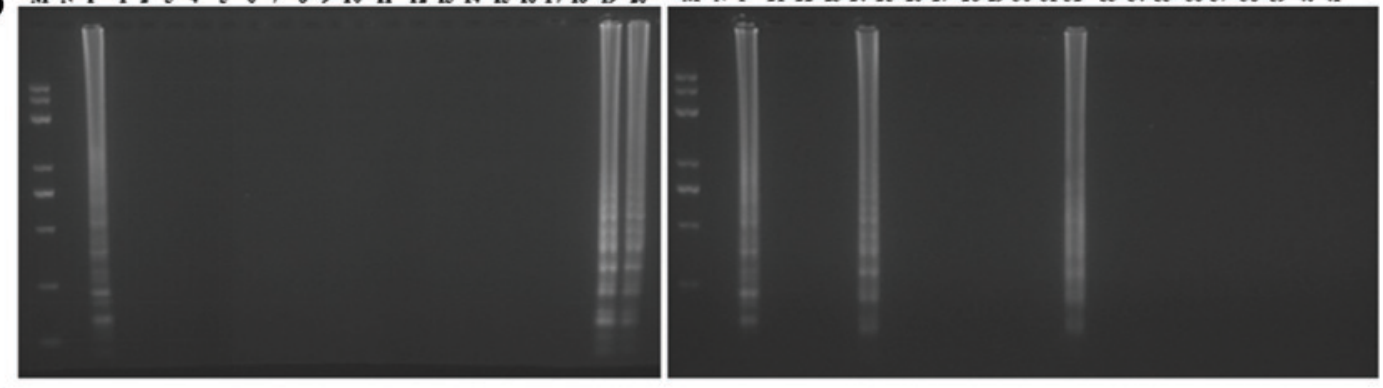

$\mathbf{E}$

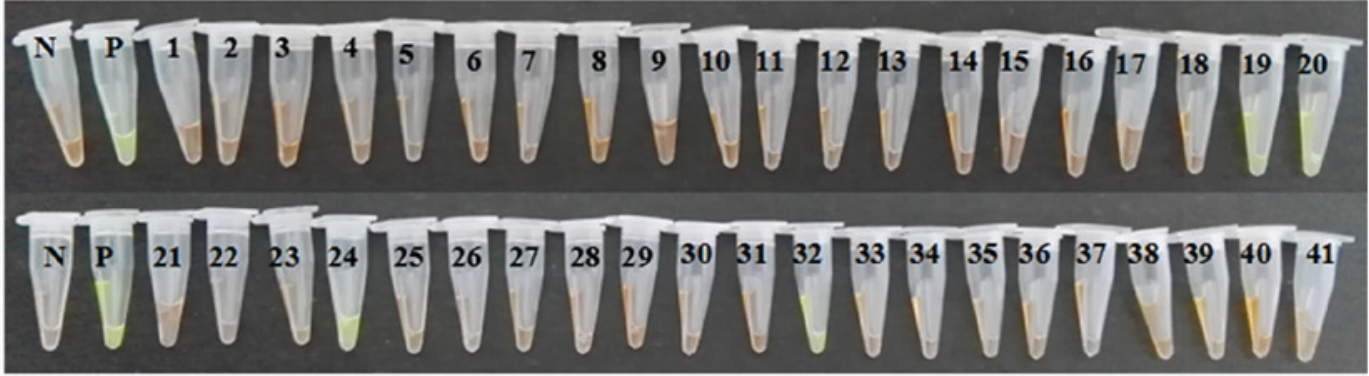

F

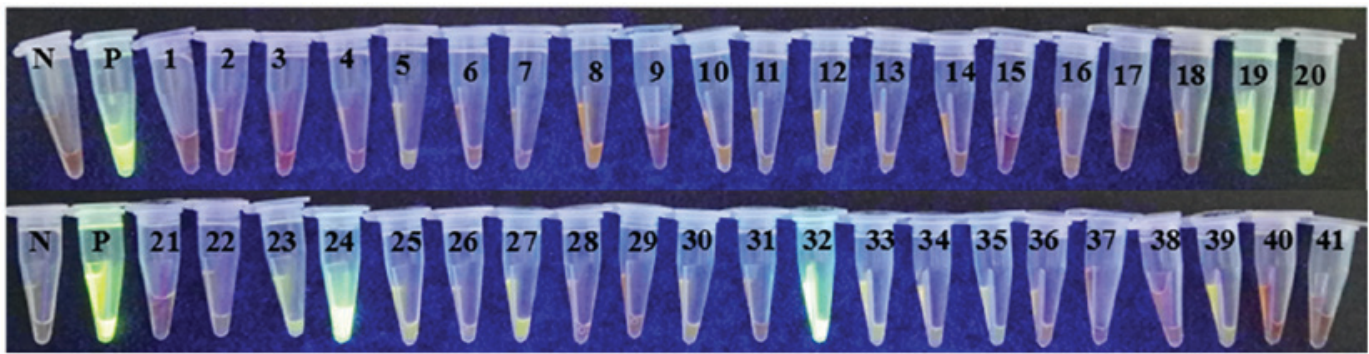

Figure 8. Detection of clinical samples in LAMP, CPA and IMSA assays. LAMP assay: (A) agarose gel electrophoresis of products obtained; (B) visualization of reactions performed with clinical samples (1-41) and SYBR-Green I under visible light; (C) visualization of reactions performed with clinical samples (1-41) and SYBR-Green I under UV light. CPA assay: (D) agarose gel electrophoresis of products obtained; (E) visualization of reactions performed with clinical samples (1-41) and SYBR-Green I under visible light; (F) visualization of reactions performed with clinical samples (1-41) and SYBR-Green I under UV light. 

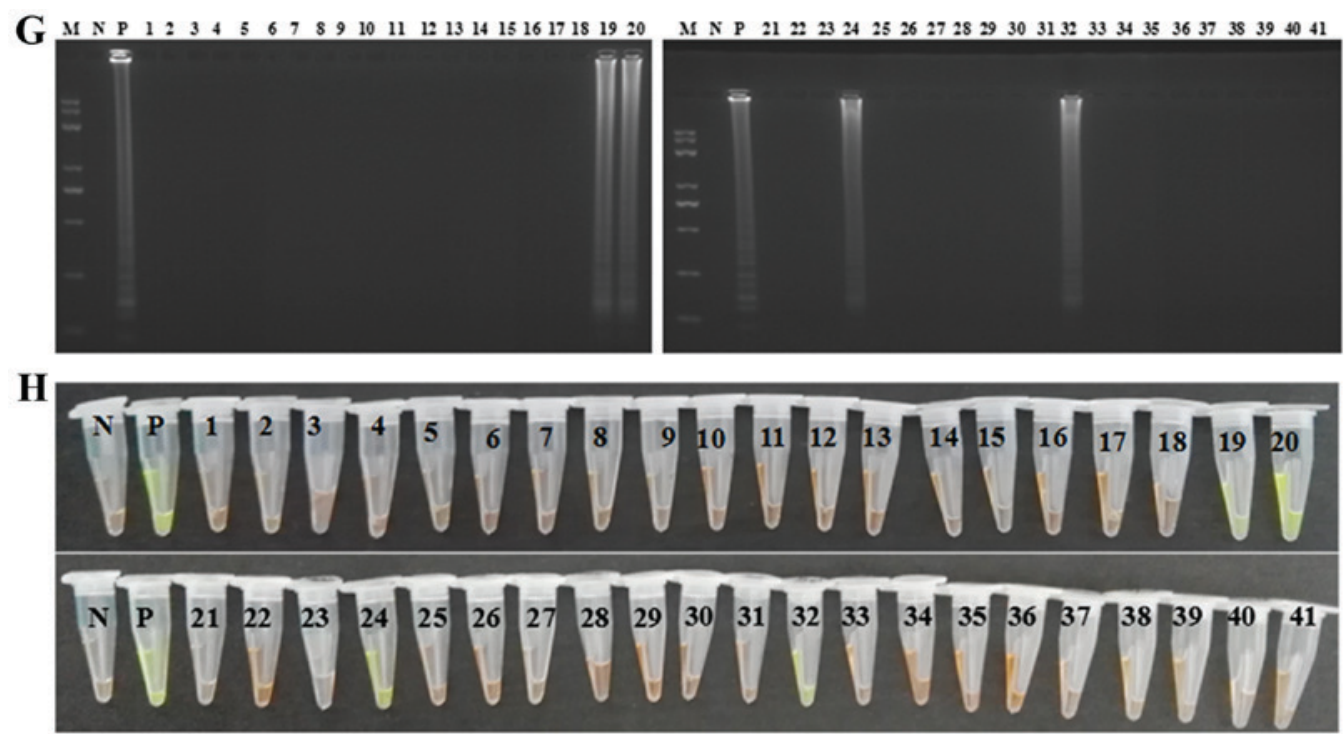

I

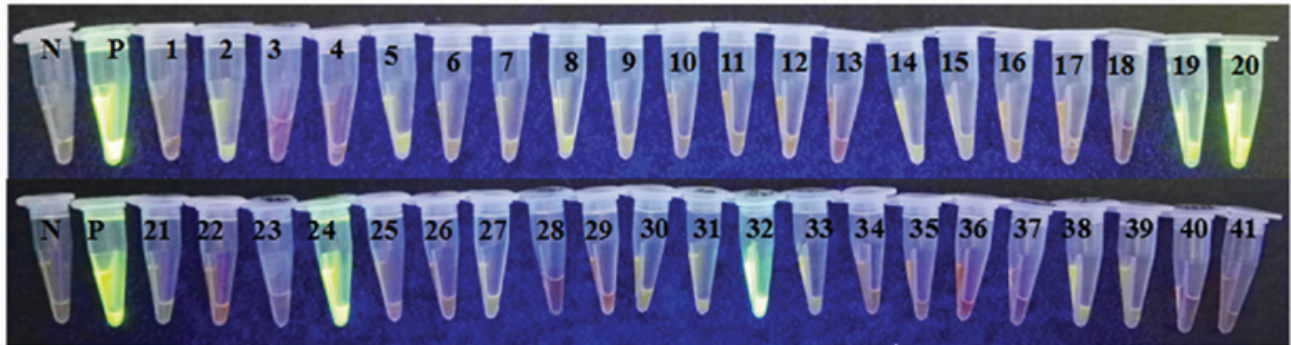

$\mathbf{J}$

Target Amplification Curves

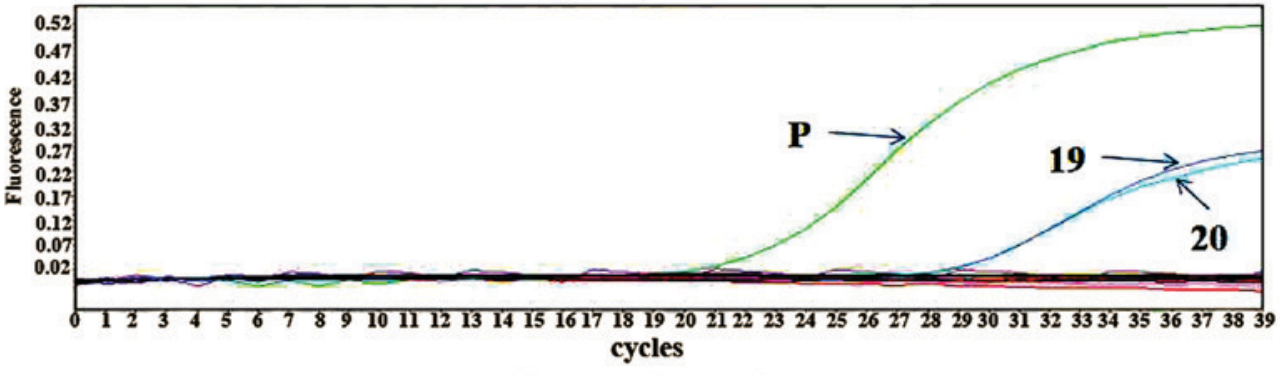

Target Amplification Curves

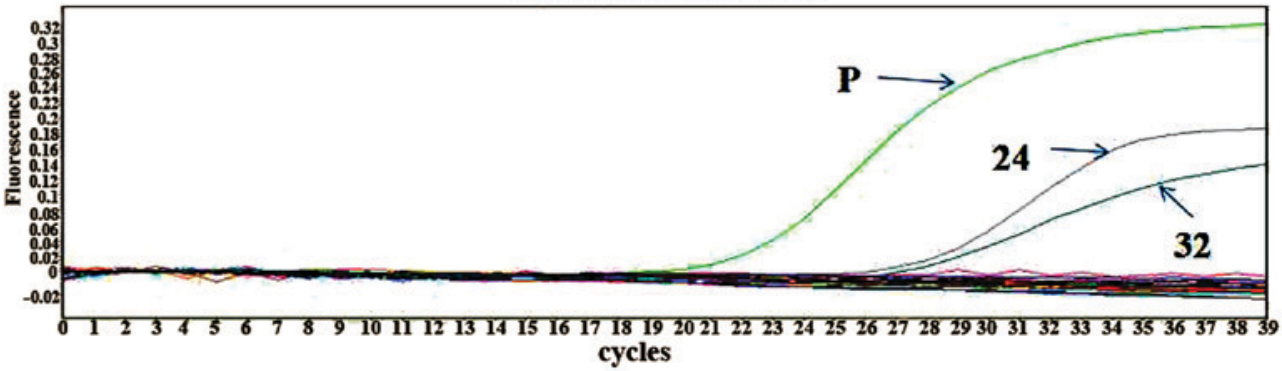

Figure 8. Continued. IMSA assay: (G) agarose gel electrophoresis of products obtained; (H) visualization of reactions performed with clinical samples (1-41) and SYBR-Green I under visible light; (I) visualization of reactions performed with clinical samples (1-41) and SYBR-Green I under UV light. (J) Reverse transcription-polymerase chain reaction amplification curves for clinical samples (1-41). LAMP, loop-mediated isothermal amplification; CPA, cross-priming amplification; IMSA, isothermal multiple-self-matching-initiated amplification; M, Trans $2 \mathrm{~K}$ plus II DNA marker; N, negative control; P, positive control (runt related transcription factor 1/runt related transcription factor 1 translocation partner 1 plasmid).

the AML1/ETO fusion gene. Furthermore, these results demonstrated the reliability of these assays for use with clinical samples, and the ease of applying these methods in small hospitals with non-specialized laboratories may eliminate delays in waiting for results from reference hematological centers. However, LAMP, CPA and IMSA assays are more expensive than RT-PCR assays ( 20.00, vs. $\sim 5.00$ Yuan, respectively). As the RT-PCR assay is a more established method, there are numerous commercially available PCR kits, and this has reduced the cost of the RT-PCR method.

In conclusion, the results of the present study demonstrated that the LAMP, CPA and IMSA isothermal assays, which were optimized in the present study, exhibited high specificity in detecting the AML1/ETO fusion gene. They exhibited no 
cross-reactivity with other fusion genes, and their clinical accuracy was equivalent to that of an RT-PCR assay, which was performed in parallel. These assays represent rapid, sensitive and specific tools, which can be applied in poorly equipped laboratories. However, these assays do not currently represent quantitative assays for the detection of minimal residual disease during follow-up. It is considered possible to generate quantitative versions of the LAMP, CPA and IMSA assays for the detection of the AML1/ETO fusion gene, and these are currently under evaluation.

\section{Acknowledgements}

Not applicable.

\section{Funding}

Financial support for the present study was provided by grants from the Science and Technology Planning Project of Guangdong Province, China (grant nos. 2014A020212300 and 2016A020215149) and the Science and Technology Special Competitive Allocation Project of Zhanjiang City (grant no. 2016A06003).

\section{Availability of data and materials}

All data generated or analyzed during this study are included in this published article.

\section{Authors' contributions}

ZY designed the study and revised the manuscript. WL designed the primers and revised the manuscript. HL performed the experiments and drafted the manuscript. RW analyzed the data and revised the manuscript. YZ analyzed the data and figures.

\section{Ethics approval and consent to participate}

All procedures involving human participants were in accordance with the ethical standards of the Ethics Committee of the Affiliated Hospital of Guangdong Medical University, and with the 1964 Helsinki declaration and its later amendments or comparable ethical standards. Informed consent was obtained from all of the individuals involved.

\section{Patient consent for publication}

Not applicable.

\section{Competing interests}

The authors confirm that they have no competing interests.

\section{References}

1. Salmon JM, Bots M, Vidacs E, Stanley KL, Atadja P, Zuber J and Johnstone RW: Combining the differentiating effect of panobinostat with the apoptotic effect of arsenic trioxide leads to significant survival benefit in a model of $t(8 ; 21)$ acute myeloid leukemia. Clin Epigenetics 7: 2, 2015.
2. Okuda T, Cai Z, Yang S, Lenny N, Lyu CJ, van Deursen JM, Harada $\mathrm{H}$ and Downing JR: Expression of a knocked-in AML1-ETO leukemia gene inhibits the establishment of normal definitive hematopoiesis and directly generates dysplastic hematopoietic progenitors. Blood 91: 3134-3143, 1998.

3. Saia M, Termanini A, Rizzi N, Mazza M, Barbieri E, Valli D, Ciana P, Gruszka AM and Alcalay M: AML1/ETO accelerates cell migration and impairs cell-to-cell adhesion and homing of hematopoietic stem/progenitor cells. Sci Rep 6: 34957, 2016.

4. Peterson LF and Zhang DE: The 8;21 translocation in leukemogenesis. Oncogene 23: 4255-4262, 2004.

5. Kumari P, LingappaKavitha B, Obula Reddy C, Mangalagowri M, Madhumathi DS, Mahadeva Prasad M, Raghavendra HV, Premalata CS, Lakshmaiah KC and Mir Mazloumi SH: A rare cytogenetic presentation of acute myeloid leukemia (AML-M2). Acta Med Iran 50: 827-830, 2012.

6. Gabert J, Beillard E, van der Velden VH, Bi W, Grimwade D, Pallisgaard N, Barbany G, Cazzaniga G, Cayuela JM, Cavé H, et al: Standardization and quality control studies of 'real-time' quantitative reverse transcriptase polymerase chain reaction of fusion gene transcripts for residual disease detection in leukemia-a Europe against cancer program. Leukemia 17: 2318-2357, 2003.

7. Wang ZD, Qin YZ, Liu YR, Xu LP, Liu DH, Liu KY and Huang XJ: Monitoring AML1-ETO mRNA levels by real-time quantitative RT-PCR in $\mathrm{t}(8 ; 21)$ acute myeloid leukemia patients after hematopoietic stem cell transplantation. Zhonghua Xue Ye Xue Za Zhi 29: 672-675, 2008 (In Chinese).

8. Cui C, Shu W and Li P: Fluorescence in situ hybridization: Cell-based genetic diagnostic and research applications. Front Cell Dev Biol 4: 89, 2016.

9. Notomi T, Okayama H, Masubuchi H, Yonekawa T, Watanabe K, Amino $\mathrm{N}$ and Hase T: Loop-mediated isothermal amplification of DNA. Nucleic Acids Res 28: E63, 2000.

10. Xu G, Hu L, Zhong H, Wang H, Yusa S, Weiss TC, Romaniuk PJ, Pickerill S and You Q: Cross priming amplification: Mechanism and optimization for isothermal DNA amplification. Sci Rep 2: 246, 2012.

11. Ding X, Nie K, Shi L, Zhang Y, Guan L, Zhang D, Qi S and Ma X: Improved detection limit in rapid detection of human enterovirus 71 and coxsackievirus A16 by a novel reverse transcription-isothermal multiple-self-matching-initiated amplification assay. J Clin Microbiol 52: 1862-1870, 2014.

12. Ding X, Wu W,Zhu Q,Zhang T, Jin W and Mu Y: Mixed-dye-based label-free and sensitive dual fluorescence for the product detection of nucleic acid isothermal multiple-self-matching-initiated amplification. Anal Chem 87: 10306-10314, 2015.

13. Viehmann S, Teigler-Schlegel A, Bruch J, Langebrake C, Reinhardt D and Harbott J: Monitoring of minimal residual disease (MRD) by real-time quantitative reverse transcription PCR (RQ-RT-PCR) in childhood acute myeloid leukemia with AML1/ETO rearrangement. Leukemia 17: 1130-1136, 2003.

14. Döhner H, Weisdorf DJ and Bloomfield CD: Acute myeloid leukemia. N Engl J Med 373: 1136-1152, 2015.

15. Niessen L and Vogel RF: Detection of Fusarium graminearum DNA using a loop-mediated isothermal amplification (LAMP) assay. Int J Food Microbiol 140: 183-191, 2010.

16. Yao X, Li P, Xu J, Zhang M, Ren R, Liu G and Yang X: Rapid and sensitive detection of didymella bryoniae by visual loop-mediated isothermal amplification assay. Front Microbiol 7: 1372, 2016.

17. Li F, Yan W, Long L, Qi X, Li C and Zhang S: Development and application of loop-mediated isothermal amplification assays for rapid visual detection of cry $2 \mathrm{Ab}$ and cry3 $\mathrm{A}$ genes in genetically-modified crops. Int J Mol Sci 15: 15109-15121, 2014.

18. Lu X, Li X, Mo Z, Jin F, Wang B, Zhao H, Shan X and Shi L: Rapid identification of Chikungunya and Dengue virus by a real-time reverse transcription-loop-mediated isothermal amplification method. Am J Trop Med Hyg 87: 947-953, 2012.

19. Ke Y, Wang Y, Wang Z, Du X, Huang L and Chen Z: Sensitive and rapid detection of blaNDM-1 in clinical samples by isothermal cross-priming amplification.J Microbiol Methods 95:215-217,2013.

20. Wozniakowski G, Niczyporuk JS, Samorek-Salamonowicz E and Gawel A: The development and evaluation of cross-priming amplification for the detection of avian reovirus. J Appl Microbiol 118: 528-536, 2015.

21. Chandra A, Keizerweerd AT and Grisham MP: Detection of puccinia kuehnii causing sugarcane orange rust with a loop-mediated isothermal amplification-based assay. Mol Biotechnol 58: 188-196, 2016.

This work is licensed under a Creative Commons Attribution-NonCommercial-NoDerivatives 4.0 International (CC BY-NC-ND 4.0) License. 